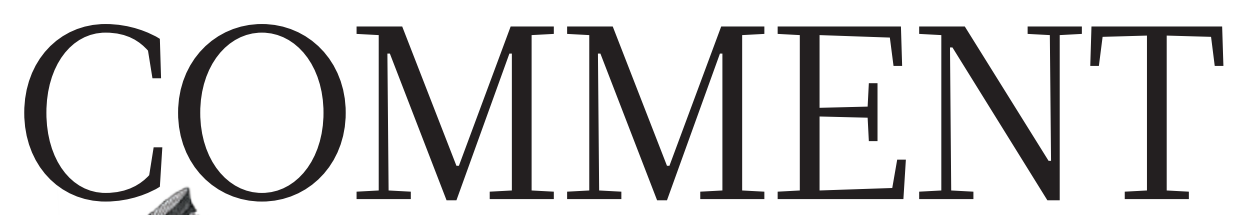

HISTORY Friends and rivals fed into Einstein's general theory of relativity $\mathbf{p . 2 9 8}$
MATHEMATICS The playful and prescient logic of Alice in Wonderland p.302
EMISSIONS Burning peat to plant oil palms in Indonesia has to stop p.305
OBITUARY Richard Heck, palladium-catalysis pioneer, remembered $\mathbf{p . 3 0 6}$

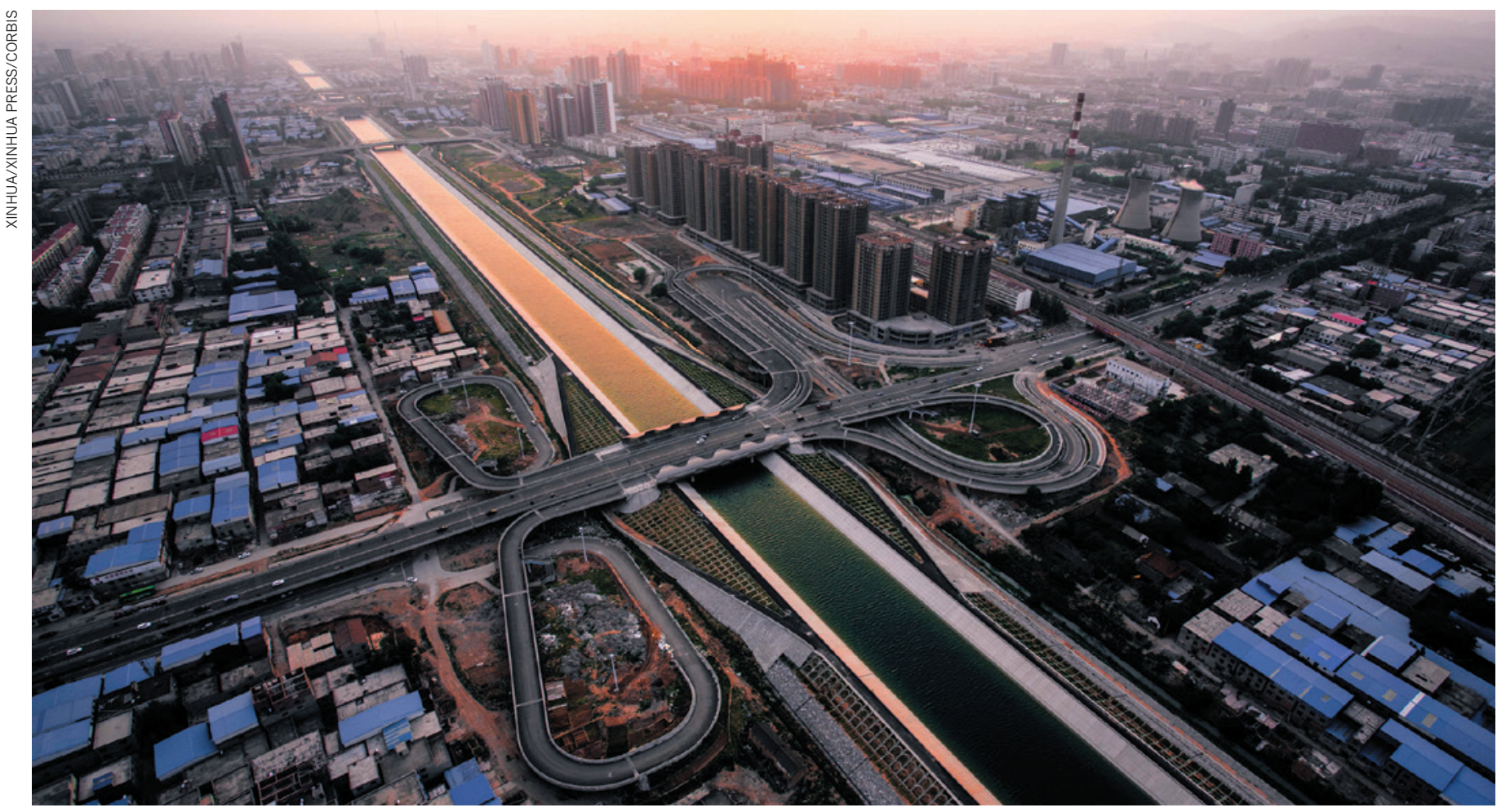

The central route of China's South-to-North Water Diversion project runs through Jiaozuo in Henan province.

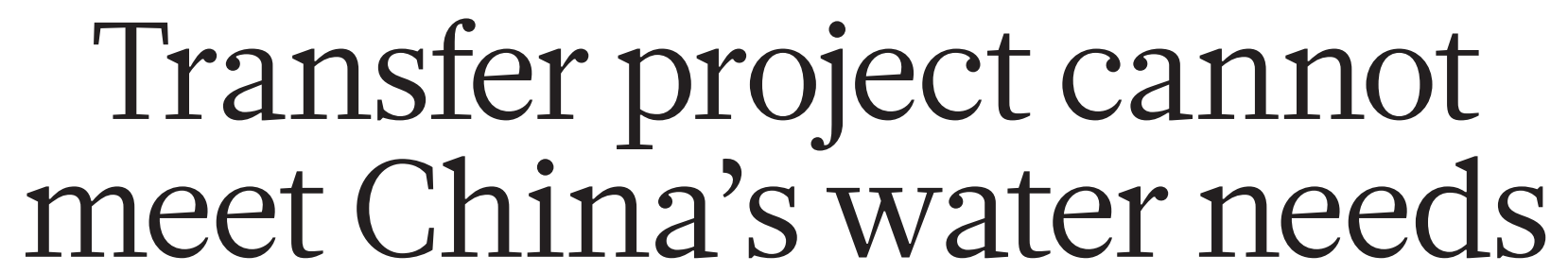

Better local water management is the way to keep pace with escalating demands, not pumping water across the country, warn Jon Barnett and colleagues.

\begin{abstract}
1most one year ago, Beijing began to receive water channelled by the

South-to-North Water Diversion (SNWD) project. The biggest inter-basin transfer scheme in the world, the SNWD project has the capacity to deliver 25 billion cubic metres of fresh water per year from the Yangtze River in China's south to the drier north by two routes - each of which covers a distance of more than 1,000 kilometres. The project connects four major river basins, three megacities, six provinces and hundreds of millions of water users and polluters.
\end{abstract}

Its success is already in question. Reservoir and canal construction costs have reportedly reached US $\$ 80$ billion, and more than 300,000 people have been displaced ${ }^{1}$. Pollution and environmental fallout, as well as high maintenance costs and water prices, make the project unsustainable both ecologically and socially. And the transfer of water does not address the underlying causes of water shortages in the north, namely pollution and inefficient agricultural, industrial and urban use - the effects of which we have been studying over the past decade.
North China could be self-sufficient in water without the transfer of water from the south. But the necessary steps - among them, improving local pollution monitoring and building better irrigation infrastructure - are inadequately implemented.

Increasing supply is viewed as the main solution to water scarcity because of the conflicting roles of the Chinese government as both entrepreneur and regulator. Incentives for economic growth in China still outweigh incentives for pollution control and limits on water extraction, despite ever stricter 
environmental laws. Many industries, such as the country's huge hydropower sector, profit from expensive solutions to boosting water supplies.

China's water system needs an overhaul. Institutional reforms must divorce profit motives from regulatory functions; data and decisions must be disclosed to the public; and the influence of the hydropower sector on water-resource management needs to be restricted. The volume of water being diverted along existing routes of the SNWD project must be reduced and extensions to the project must be shelved.

Better local management of resources is the only way to bring secure and sustainable water to all parts of China.

\section{BIG WATER}

China's history of grand water-engineering projects is almost as old as the nation itself, and is inextricably knit with the country's politics, development and self-image. The first dam was built in around $600 \mathrm{BC}$ at Anfeng Tang in eastern China. It created a still existing reservoir 100 kilometres in circumference that could irrigate an area of 24,000 square kilometres. Ever since, most of China's watermanagement systems have been created and run by the state.

The SNWD project transports water in two ways (see 'South-to-north water transfer'). Its eastern route has the capacity to supply up to 14.8 billion cubic metres of water per year to the provinces of Jiangsu, Anhui, Shandong and Hebei, and to the city of Tianjin. The water travels through a system of pumps, rivers, lakes, reservoirs and canals that includes the Grand Canal, which was built around $500 \mathrm{BC}$. Its central route will provide up to 9.5 billion cubic metres of water per year, including one-third of Beijing's water, from the Danjiangkou reservoir on the Han River (a tributary of the Yangtze). During the construction of this route, the water level of the reservoir was raised by 13 metres, which resulted in the resettlement of 180,000 people from Shiyan city and 160,000 from Nanyang city.

A third, western, route is planned that would divert up to 20 billion cubic metres of water from three tributaries of the upper Yangtze through tunnels to the upper reaches of the Yellow River. Its path is under debate and there has been no commitment to commencing its construction nor any indication of when a decision might be made ${ }^{1}$. In our view, the scope for improving water management makes this extra route unnecessary.

Without question, northern China, which includes the Hai, Huai and Yellow river basins, is short of water. The region's annual per capita water availability is only around half of the international threshold for water stress ${ }^{2}$. Water scarcity is most acute in the Hai basin, where Beijing is located. Farms and cities
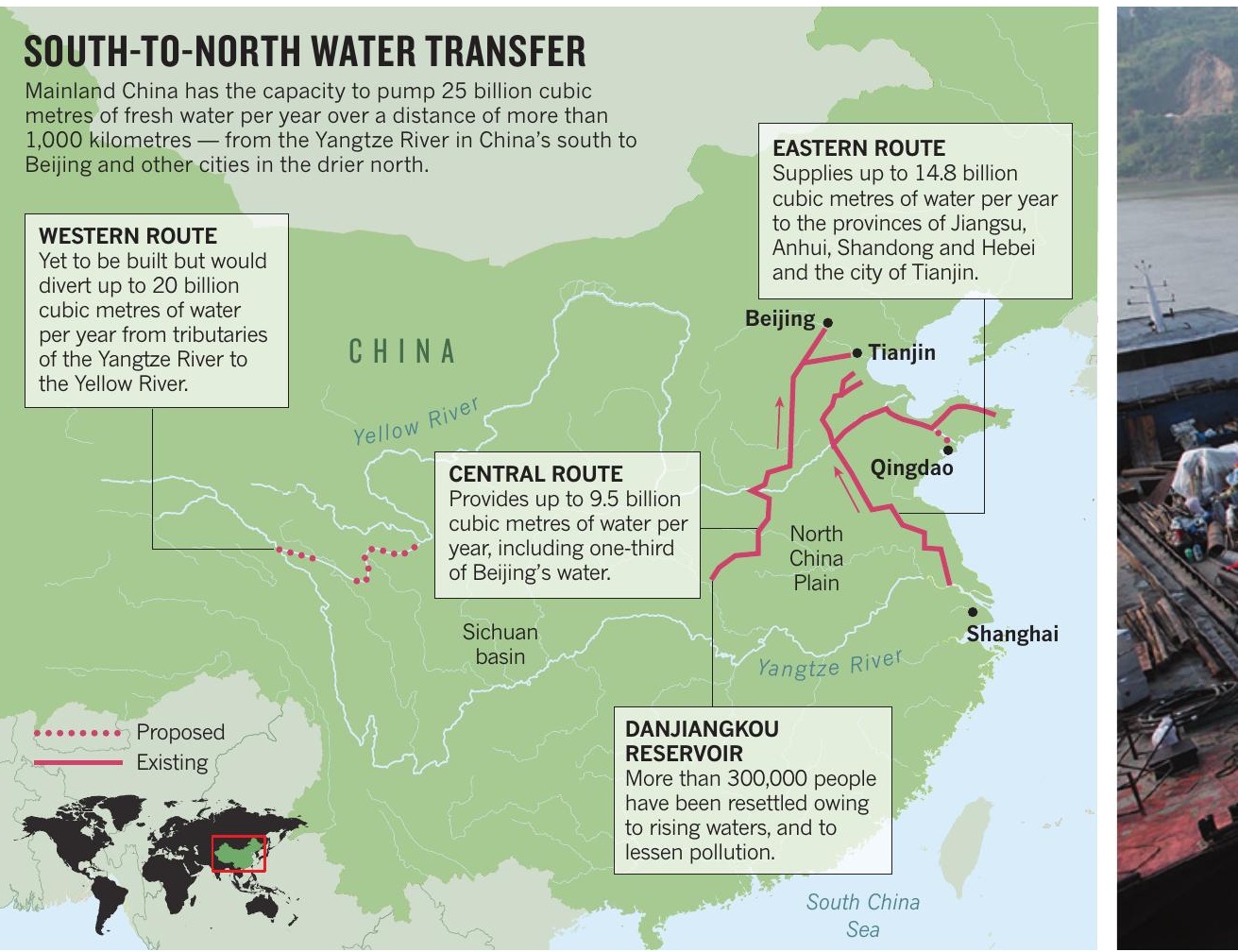

have increasingly drawn on groundwater such that $50 \%$ of aquifers in the North China Plain are now below sea level. This scarcity is compounded by poor water quality in up to $60 \%$ of water in the rivers of the north, which further reduces the supply of clean water for drinking and domestic use ${ }^{2}$.

The problem is more a scarcity of management than of natural water ${ }^{3}$. Inefficient agricultural production consumes about $75 \%$ of the region's water and is growing rapidly. In areas where cereal crops are flood irrigated, losses can exceed 50\%. In addition, the lack of storage systems along the Yellow River means that farmers must use water when it is made available - not necessarily when they need it ${ }^{3}$.

The idea of water scarcity in the north is perpetuated by China's government for several reasons. It justifies taking water from the south to achieve President Xi Jinping's ambitions for a mega-economic region that encompasses Beijing, Tianjin and Hebei. And it serves the interests of those in the business of supplying water, including China's huge, state-owned water-engineering firms.

But the SNWD project does not ensure a reliable supply to the north. Pollution is a pervasive risk. In response to complaints about quality from provinces receiving water, the National Development and Reform Commission ordered changes in land use across the Danjiangkou reservoir catchment area to reduce urban and agricultural run-off. Development has been prohibited in some areas, and in others communities have been resettled. The use of pesticides and fertilizers has been limited and industry is subjected to stricter pollution controls. In 2015, Danjiangkou reservoir won a national award for water quality - at the cost of the impoverishment of the hundreds of thousands of people who were forced to move.

And there are other costs. Wang Mengshu, a civil engineer at Beijing Jiaotong University, has suggested that the expense of maintaining the SNWD conduits was vastly underestimated. The price of transferred water will be too expensive for farmers, who will therefore continue to exploit groundwater ${ }^{4}$.

The SNWD project also poses risks in source areas. Claims of abundant water in the Yangtze hide the fact that shortages do occur. In the past decade, there have been two severe droughts in the Yangtze basin. And periods of water scarcity are more likely in the future because of an increase in the number of withdrawals and dams, as well as the effects of urbanization and climate change. The timing of water transfers is therefore important: should extractions from the Yangtze occur at times of low flow, saline waters from its estuary could be drawn in. Nearby Shanghai's population of 24 million would then face critical water shortages until discharge levels rose again ${ }^{5}$.

Governance of the SNWD project remains unresolved. Both the state-owned HydroChina Corporation and the central government's SNWD project construction committee seek to control the flow of the project's waters, even though this is a core responsibility of the Chinese Ministry of Water Resources. Corporatization of the state is reaching into the management of water, 


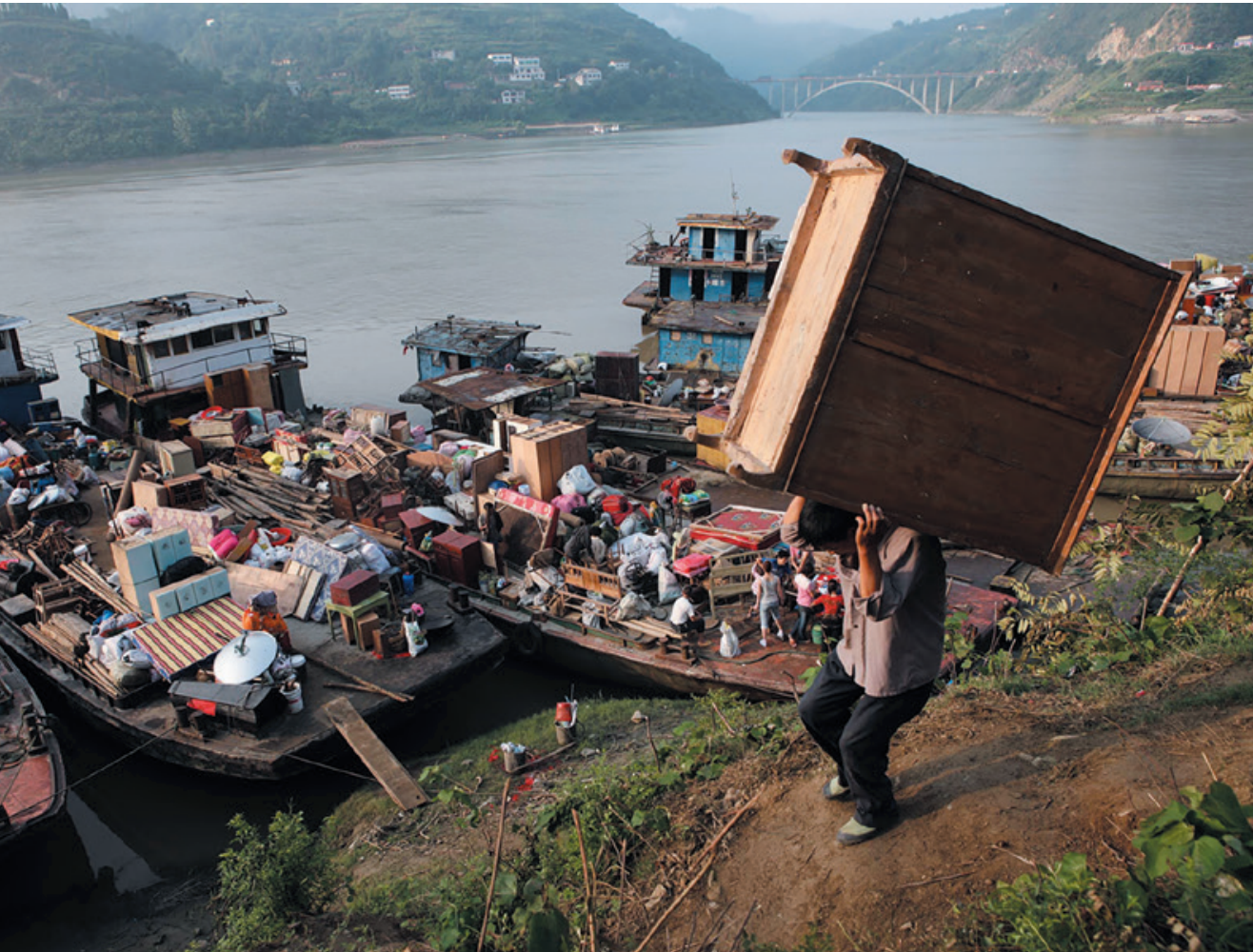

Hundreds of thousands of residents were relocated during construction of the project.

creating tension between motives and profit, uncertainty about roles and responsibilities and impediments to coordinated management of the nation's water courses.

\section{BEYOND PIPES}

In cities, rainwater harvesting and wastewater recycling can meet much of the demand. According to Qiu Baoxing, a former viceminister of the Chinese Ministry of Housing and Urban-Rural Development, the SNWD project could have been avoided if one-third of buildings in Beijing collected rainwater. Increased investment in treatment systems, efficient irrigation and the monitoring and enforcement of pollution levels can also improve the supply of usable water ${ }^{2,6,7}$. Lower-quality water could be used for urban landscaping and industry, and some water-intensive activities could be moved to the south.

Such solutions require coordination with local governments, which are driven by growth and profit. When bureaucrats behave like businessmen and state-owned enterprises operate like private corporations, even strong environmental laws have little effect ${ }^{6}$. By contrast, the SNWD project is easy to administrate, politically feasible and drives growth.

There are signs of change. Since 2006, environmental targets have been included in performance criteria for local leaders ${ }^{6}$. And there have been experiments in increasing disclosure to the public of data on the environmental performance of firms ${ }^{7}$. Both measures have made local governments and businesses

more accountable for environmental standards. They have led to lower levels of pollution and encouraged investment in cleaner technologies and the closure of inefficient plants. But the enforcement of standards and laws varies from region to region - the economic imperative still dominates in less-developed regions - and data can be falsified ${ }^{6}$.

The Chinese government's authority rests on maintaining social stability and economic growth. The government must therefore respond to challenges such as corruption, public-health issues and inequality ${ }^{8}$. Given improved living standards, greater levels of education and the

proliferation of social media, high levels of pollution can no longer be ignored. Both the central and local

\section{"The problem is more a scarcity of management than of natural water."}

governments in China must be seen to be controlling pollution, which can lead to secrecy and misinformation. In our experience, detailed data on the flow of water and pollution levels in major rivers can be difficult to obtain and must often be paid for.

\section{SMALL STEPS}

As is already done for air pollution, the central and local Chinese governments should disclose information on water to demonstrate the responsible management of resources to the public. Providing accessible information about the allocation of water rights - as well as the allocation of water itself to provinces, irrigation districts and farmers would increase public trust in the system and improve the accountability of water managers, local government and firms ${ }^{6}$.

Local environmental-protection bureaus should be given the autonomy and resources to collect and analyse monitoring data independently and to enforce pollution standards. Exporters that rely on foreign investment must increasingly comply with standards and regulations as their parent companies and consumers demand proof of environmental responsibility. Industrial water users should consider cleaner production as a path to savings, new markets and improved competitiveness ${ }^{9}$.

In agriculture, losses can be reduced by lining irrigation canals with concrete. Water should be supplied only at times when irrigation is necessary ${ }^{3}$. The rotation of wheat with higher-value crops that take less water to grow, such as peanuts, will also improve the efficiency of water use ${ }^{10}$.

Investment in new technologies is needed, including systems to separate urban water according to quality, recycle waste water, encourage water conservation and improve the harvesting of rainwater. This would require performance targets to be set for local managers, as well as investment in and incentives for building smaller-scale water infrastructure. Campaigns to increase public awareness of water issues should also be implemented.

Constraining the influence of the hydropower sector on water-resource management will help to shift public investment towards these smaller-scale technologies. The sector is already expanding into overseas markets to compensate for reduced domestic demand in the wake of disquiet about water pollution.

As its limitations become clear, the SNWD project might well mark the nadir of big-engineering solutions to China's water problems.

Jon Barnett is professor and Australian Research Council Future Fellow, Sarah Rogers is a research fellow, and Michael Webber, Brian Finlayson and Mark Wang are professors, in the School of Geography, University of Melbourne, Victoria, Australia. email:jbarn@unimelb.edu.au

1. Crow-Miller, B. Water Altern. 8, 173-192 (2015)

2. Jiang, Y. Environ. Sci. Policy 54, 106-125 (2015).

3. Webber, M., Barnett, J., Finlayson, B. \& Wang, M. Global Environ. Chang. 18, 617-625 (2008).

4. Webber, M. Making Capitalism in Rural China (Edward Elgar, 2012).

5. Chen, D. et al. Appl. Geogr. 45, 303-310 (2013).

6. Wang, A. L. Harvard Environ. Law Rev. 37, 365-440 (2013).

7. Wang, H. et al. J. Environ. Mgmt 71, 123-133 (2004).

8. Heberer, T. \& Schubert, G. (eds) Regime Legitimacy in Contemporary China: Institutional Change and Stability (Routledge, 2009).

9. Yee, W.-H., Lo, C. W.-H. \& Tang, S.-Y. China Quart. 213, 101-129 (2013)

10. Yang, X. et al. PLoS ONE 10, e0115269 (2015). 